\title{
Dietary diversity predicts dietary quality regardless of season in 6-12-month-old infants in south-west Ethiopia
}

\author{
Mekitie Wondafrash ${ }^{1,2, *}$, Lieven Huybregts ${ }^{2,3}$, Carl Lachat ${ }^{2,4}$, Kimberley P Bouckaert ${ }^{2,4}$ \\ and Patrick Kolsteren ${ }^{2,4}$ \\ 'Department of Population and Family Health, College of Public Health and Medical Sciences, Jimma University, PO \\ Box 378, Jimma, Ethiopia: ${ }^{2}$ Department of Food Safety and Food Quality, Faculty of Bioscience Engineering, Ghent \\ University, Ghent, Belgium: ${ }^{3}$ Poverty, Nutrition and Health Division, International Food Policy Research Institute, \\ Washington, DC, USA: ${ }^{4}$ Unit of Nutrition and Child Health, Institute of Tropical Medicine, Antwerp, Belgium
}

Submitted 29 July 2015: Final revision received 12 February 2016: Accepted 23 February 2016: First published online 4 April 2016

\begin{abstract}
Objective: Simple, cost-effective and convenient instruments like food groupbased scores are proposed to assess micronutrient adequacy of children in developing countries. We assessed the predictive ability and seasonal stability of a dietary diversity score (DDS) to indicate dietary quality of infants.

Design: A $24 \mathrm{~h}$ dietary recall assessment was carried out on a sample of 320 and 312 breast-fed infants aged 6-12 months during harvest (HS) and pre-harvest (PHS) seasons, respectively, in Ethiopia. DDS was calculated based on seven food groups, while mean micronutrient density adequacy (MMDA) was calculated for eight micronutrients. Multiple linear regression models were used to assess the relationship between DDS and MMDA, and differences in nutrient intake between the two seasons. A receiver-operating characteristic curve analysis was performed to derive DDS cut-offs that maximized sensitivity and specificity of assessing dietary quality.

Setting: The study was conducted in the catchment of the Gilgel Gibe Field Research Centre of Jimma University, south-west Ethiopia.

Results: The mean (SD) DDS for HS and PHS was 2.1 (0.94) and 2.3 (1.1), respectively. The DDS was associated with MMDA $(\beta=0.045, P<0.0001$ in HS; $\beta=0.044, P<0001$ in PHS). A DDS of $\leq 2$ food groups best predicted 'low' MMDA ( $<50 \%$ ) with $84 \%$ and $92 \%$ sensitivity, $36 \%$ and $43 \%$ specificity, and $47 \%$ and $51 \%$ correct classification for the HS and PHS, respectively.

Conclusions: DDS is predictive of dietary quality of breast-fed infants. The study supports the use of DDS to indicate inadequate intakes of micronutrients by breast-fed infants in different seasons.
\end{abstract}

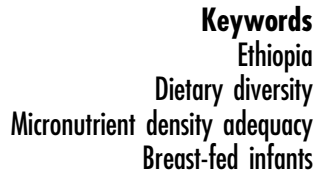

eywords

ersity

Breast-fed infants
Ethiopia has one of the highest rates of child malnutrition $^{(1)}$. The nutritional status is influenced by many interrelated factors $^{(2)}$. Among others, Ca, Zn, Fe, vitamin A and iodine deficiencies are common in Ethiopia, and have been attributed to low intake and low bioavailability ${ }^{(1,3-5)}$. Moreover, the monotonous consumption of staple foods in complementary feeding fails to meet the daily requirements of infants and young children ${ }^{(6,7)}$.

The assessment of nutritional status has been limited to anthropometry due to the time- and personnel-consuming nature of dietary assessments ${ }^{(8)}$. As a result, an intake assessment of nutrients, single food items or a combination of foods to predict the risk of one or more health-related problems has emerged as an alternative approach to actual quantification of nutrient intakes ${ }^{(9)}$.
However, the problem of diagnostic ability of several dietary indices to predict health outcomes, dietary quality or nutritional status has not been resolved for some reasons $^{(9)}$.

The dietary diversity score (DDS) is a simple indicator of dietary diversity and is based on measuring the number of food groups consumed over a given reference period. A higher dietary diversity is associated with an adequate intake of essential micronutrients. The score has been shown to be associated with nutrient density ${ }^{(10,11)}$ and nutrient adequacy ${ }^{(12,13)}$ in breast-fed and non-breast-fed children. To date, only one study has looked into the stability of a summary child feeding index (of which DDS is a component) and its association with child growth over different time points ${ }^{(14)}$. As the seasonal influence on 
dietary intake and nutrient density of local foods was demonstrated to be substantial, seasonal differences can be expected to affect the validity of simple dietary indices to predict dietary quality ${ }^{(15)}$.

To our knowledge, there is no study that has assessed the validity of DDS using quantitative dietary intake data collected from breast-fed children aged 6-12 months in two distinct seasons. The aim of the present study was therefore to determine how seasonality affects the validity of a DDS in predicting nutrient adequacy of complementary foods for breast-fed infants in south-west Ethiopia. We also identified an appropriate cut-off to predict 'low' or 'higher' dietary quality and assessed differences between seasons.

\section{Methods and participants}

\section{Sampling and design}

A census of all infants aged 6-12 months was carried out within the Gilgel Gibe Field Research Center of Jimma University (south-west Ethiopia). Infants aged 6-12 months and born in the Gilgel Gibe Field Research Center, who had a biological mother or female caregiver, who presented no serious illness or malformation affecting anthropometric measurement and had no intention of leaving the area in the coming 6 months were listed. This procedure was applied in two seasons: during harvest season (HS) from October to December 2009 and pre-harvest season (PHS) from June to August 2010. A total of 320 and 312 eligible infants were included in the HS and PHS, respectively.

\section{Study setting}

The study was conducted in nine kebeles (smaller government unit) of the catchment area of Gilgel Gibe Field Research Center of Jimma University, south-west Ethiopia. The total population within the area in 2011 was 54528 , of whom 15719 (28.8\%) were located in urban and 38809 $(71.2 \%)$ in rural communities. The main source of income for the community is farming and raising livestock. Maize, sorghum and teff (a species of Eragrostis native to Ethiopia) are commonly grown food crops in the area. Food consumption patterns of the population are expected to be different based on the differences in food availability in the two seasons.

\section{Data collection}

We used pre-tested interviewer-administered questionnaires to collect data on socio-economic and demographic characteristics and infant feeding practices. Questions were adapted from Demographic and Health Survey questionnaires ${ }^{(16)}$ and the WHO guideline for the assessment of infant and young child feeding ${ }^{(17)}$. We collected dietary intake data using a multiple-pass $24 \mathrm{~h}$ recall questionnaire adapted for commonly consumed foods in the study area ${ }^{(18)}$. Data collectors were fluent in local languages (Amharic and Afan Oromo) and received a $5 \mathrm{~d}$ intensive training from the principal investigators.

\section{Dietary intake assessment}

Two $24 \mathrm{~h}$ recalls of the infants' diet were conducted in each season. Compared with a weighed record method, the interactive $24 \mathrm{~h}$ recall method is less expensive and burdensome for the respondents.

Spoons and graduated bowls were provided to mothers/ caregivers weeks before the interview. They were told to use them during the coming weeks. Instructions were provided on how to estimate the portion sizes consumed by their infant using the utensils provided and prestandardized household measures. Two sources of recipe data were used to convert composite dishes to ingredients. First, we collected recipe data of common composite dishes by asking five mothers to prepare them. For this purpose, ingredients were weighed using scales during the preparation. Second, we used averaged recipe data that were available from the Ethiopian traditional recipe table ${ }^{(19)}$. During the $24 \mathrm{~h}$ recall we assessed the recipe qualitatively and matched it with the best available recipe. Foods that come in discrete units were recalled and converted into weights by using conversion lists that were compiled from weighing all such foods. A $1 \mathrm{~g}$ precision laboratory scale (Ohaus Corp., USA) was used to record weights for the different sizes of household measures, bowls and spoons provided to the mothers or caregivers.

During the interview, mothers were requested to show the type and amount of foods the infant had consumed in the last $24 \mathrm{~h}$. A pre-recorded conversion table was used that converted volumetric estimations of gruels and porridges to weight equivalents according to three reported consistencies (thin, medium and stiff). All days of the week were represented in the final sample in order to offset day-of-the-week effects on food or nutrient intakes. The two $24 \mathrm{~h}$ dietary recalls were separated by $\pm 15 \mathrm{~d}$ in both seasons.

Food composition data were obtained from various sources. Values for energy and water-soluble vitamins were compiled from the Ethiopian food composition table and the FAO food composition table for Africa ${ }^{(20-22)}$. Some missing foods and nutrient values were obtained from an analysis paper ${ }^{(6)}$, the food tables for East Africa ${ }^{(23)}$ and the US Department of Agriculture ${ }^{(24)}$. Missing nutrient values were imputed using the formula of Gibson and Ferguson $^{(18)}$. We were only able to use retinol and trans- $\beta$-carotene concentrations to calculate the vitamin A activity due to the lack of data on other carotenoids ${ }^{(25)}$. We used the Lucille food intake program ${ }^{(26)}$ to enter consumed foods and calculate corresponding nutrient values.

\section{Dietary diversity score and micronutrient density adequacy}

Food group consumption was recalled separately during the second day of the $24 \mathrm{~h}$ dietary recall using the food 
group classification suggested by Dewey et al. ${ }^{(11)}$. The DDS was obtained by summing the number of food groups consumed in the previous $24 \mathrm{~h}$ by the infant. The following seven food groups were included: (i) grains, roots and tubers; (ii) legumes and nuts; (iii) dairy products; (iv) flesh foods; (v) eggs; (vi) vitamin A-rich fruits and vegetables (>130 retinol equivalents/100 g); and (vii) other fruits and vegetables. As recommended in the WHO infant and young child feeding practices measurement guide $^{(27)}$, fats and oils were not used in the analyses.

To validate the DDS, we used the average of $2 \mathrm{~d}$ micronutrient intakes from complementary foods to calculate the micronutrient density adequacy (MDA) scores as proposed by Dewey et al. ${ }^{(11)}$. MDA of complementary foods was calculated based on nutrient density (per $418 \mathrm{~kJ} / 100 \mathrm{kcal}$ ) rather than absolute nutrient intake, in order to account for the unknown variability in breast milk intake. Micronutrient densities per $418 \mathrm{~kJ} / 100 \mathrm{kcal}$ of complementary foods were calculated for two age categories (6-8 months and 9-12 months) and were compared with estimated desired nutrient densities. The desired nutrient densities were calculated for each nutrient using equation (1) as suggested by Dewey et al. ${ }^{(11)}$ :

Desired nutrient density of complementary foods for nutrient $x$

$=[\mathrm{RNI}$ of nutrient $x-($ concentration of nutrient $x$ in breast milk $\times$ 'average' breast milk intake volume)/ energy needed from complementary foods when breast milk intake is 'average'] × 100 .

Eight micronutrients (vitamins A and C, thiamin, riboflavin, niacin, $\mathrm{Fe}, \mathrm{Ca}$ and $\mathrm{Zn}$ ) were used for the calculation of MDA. The contribution to the overall nutrient intake by breast milk was subtracted from the Recommended Nutrient Intake (RNI) of each micronutrient to obtain the required amount from complementary foods for all breastfed children. We assumed an 'average' breast milk intake of 674 and $616 \mathrm{~g} / \mathrm{d}$ for 6-8- and 9-12-month-old infants, respectively, and we used the breast milk concentration of each micronutrient as documented by $\mathrm{WHO}^{(28)}$. The RNI values of vitamins were taken from WHO/FAO ${ }^{(29)}$. Bioavailability assumptions were made for $\mathrm{Ca}, \mathrm{Fe}$ and $\mathrm{Zn}$ in order to compare nutrient intakes and requirements. For $\mathrm{Ca}$, Fe and $\mathrm{Zn}$, 'absorbed' recommended amount was the basis for the calculation. For our analysis, 30\% and $10 \%$ of the recommended intake of $\mathrm{Ca}$ and $\mathrm{Fe}$ in complementary foods were assumed absorbed, respectively ${ }^{(11)}$. Following international recommendations, $15 \%$ bioavailability was assumed for $\mathrm{Zn}$ from low-bioavailability foods ${ }^{(30)}$. The percentage of $\mathrm{Ca}$ and $\mathrm{Fe}$ absorbed from breast milk was estimated at $30 \%^{(31)}$ and $20 \%^{(32)}$, respectively, while the percentage of $\mathrm{Zn}$ absorbed from breast milk was estimated at $50 \%{ }^{(33)}$. The estimated daily energy requirements from complementary foods, assuming 'average' breast milk intake, were $845 \mathrm{~kJ}(202 \mathrm{kcal})$ at 6-8 months and $1284 \mathrm{~kJ}$ (307 kcal) at 9-11 months ${ }^{(25)}$.

After determining the desired nutrient density for each of the eight nutrients, the MDA score per $418 \mathrm{~kJ} / 100 \mathrm{kcal}$ of complementary foods was calculated using equation (2) as the percentage of the desired nutrient density fulfilled by the complementary foods of breast-fed infants aged 6-8 and 9-12 months:

MDA for nutrient $x$

$=\{[$ (intake of nutrient $x /$ complementary food energy intake $)$ $\times 100] /$ desired nutrient density $\} \times 100$.

The mean of the individual MDA values was calculated to give mean micronutrient density adequacy (MMDA), which was then capped at $100 \%$. We evaluated the sample's MMDA using two arbitrary cut-offs, used previously $^{(10,11)}$ to assess dietary quality: MMDA $<50 \%$ and MMDA $\geq 75 \%$, representing 'low' and 'higher' dietary quality, respectively.

We compared the observed nutrient intakes with the desired nutrient intakes from complementary foods assuming every child had an 'average' breast milk intake $(\mathrm{g} / \mathrm{d})$ as proposed by WHO for each age group ${ }^{(28)}$. This time the desired nutrient density per $418 \mathrm{~kJ} / 100 \mathrm{kcal}$ of complementary food was not calculated.

We assessed the contribution of the seven complementary food groups to the mean daily intakes of energy, protein, fat and micronutrients calculated from the two $24 \mathrm{~h}$ dietary recalls and disaggregated by season to understand which groups were responsible for the intakes of energy and micronutrients by the target infants. This provides additional information on the pattern of food group contributions to nutrient intakes.

\section{Anthropometry}

Anthropometric measurements were standardized through repetitive exercises. Recumbent length was measured on an infant measuring board and recorded to the nearest $0 \cdot 1 \mathrm{~cm}$ (SECA 210, Hamburg, Germany). Weight of the infant was measured naked or with very light clothes using mother-child digital scales and recorded to the nearest $0 \cdot 1 \mathrm{~kg}$ (SECA Uniscale). Age was recorded from birth certificates or immunization cards as often as possible. If the age was absent, local events calendars were used to help the mother or caregiver estimate the approximate age of the child. Most of the anthropometric data collectors used in the HS were available for anthropometric measurement in the PHS after 5-6 months.

\section{Data analysis}

The anthropometric measures were converted into $Z$-scores of weight-for-age (WAZ), length-for-age (LAZ) and weightfor-length (WLZ) based on the WHO 2006 growth reference $^{(34)}$. Underweight, wasting and stunting were defined as $\mathrm{WAZ}<-2$, WLZ $<-2$ and $\mathrm{LAZ}<-2$, respectively. Severe 
underweight, wasting and stunting were defined as WAZ $<-3$, WLZ $<-3$ and LAZ $<-3$, respectively.

We constructed an asset-based proxy to estimate the socio-economic status of the included households. Items included were ownership of cattle, house construction materials, land (homestead, land under cultivation, fallow land) and ownership of other household assets. For household assets, categories for each item were 'owned' and 'not owned' by the household. The first principal component ( $56 \%$ of the variance) from a principal components analysis was divided in tertiles and used as a proxy for socio-economic status ${ }^{(35)}$.

Descriptive analyses were conducted for sociodemographic data, nutritional status and percentage of the study population consuming each food group in relation to dietary diversity stratified by season. Means and standard deviations were reported for continuous data that were normally distributed. Differences in means were statistically tested using a Student $t$ test, while a $\chi^{2}$ test was used to compare categorical variables. As most distributions of nutrient intake data were skewed, we first presented median intakes and interquartile ranges by season for descriptive purposes. Second, we used multiple linear regression models to compare the mean energy and nutrient intakes by season, adjusting for significant differences in characteristics between the two seasons (HS and PHS).

We looked at bivariate associations between child, caregiver, household characteristics and MMDA using simple linear regression models. Every variable with a modest association $(P<0 \cdot 20)$ was a candidate to be included in the multivariate analysis. A full model assessing the relationship between DDS and MMDA was compiled after which non-significant variables were removed by a backward procedure using a likelihood ratio test $(P<0 \cdot 05)$.

We determined cut-offs in terms of number of food groups at which we could classify infants at a reasonable MMDA with sufficient sensitivity and acceptable specificity. Hence, the performance of the DDS to indicate dietary quality was evaluated by a receiver-operating characteristic curve analysis. The area under the curve (AUC) represents the probability of the DDS as an indicator of dietary quality. An AUC above 0.50 indicates prediction of dietary quality by the DDS; the higher the AUC value of a dietary diversity indicator, the better the prediction.

Based on previous analysis ${ }^{(10,11)}$, sensitivity and specificity stratified by season were determined to compare the performance of the DDS in correctly differentiating cases with MMDA <50\% ('low' MMDA) or $\geq 75 \%$ ('higher' MMDA) for infants 6-8 and 9-12 months of age. When using the DDS to predict 'low' MMDA, the sensitivity indicates the fraction of infants who are correctly classified as having 'low' MMDA; whereas the specificity indicates the fraction of infants who are above the cut-off for 'low' MMDA and are correctly classified as such by the DDS. For 'higher' MMDA, the sensitivity indicates the fraction of infants who are correctly classified as having 'higher' MMDA, whereas the specificity refers to the fraction of infants who are below the cut-off for 'higher MMDA' and are correctly classified as such by the DDS. Data were analysed with the statistical software package Stata version 12.0. Statistical significance was set at $5 \%$ and all tests were two-sided.

\section{Results}

Data were collected from 320 and 312 infants during HS and PHS, respectively. A total of forty-five infants (twentyfour in HS and twenty-one in PHS), for whom MMDA could not be calculated, were excluded from analyses. Of these forty-five, there were fifteen infants (ten in HS and five in PHS) from whom incomplete dietary intake data were collected by the interviewers, twenty-one caregivers were not breast-feeding their children (eleven in HS and ten in PHS) and nine caregivers were unable to provide a reliable estimate for their child's age (three in HS and six in PHS). The LAZ, WAZ and WLZ of excluded observations were not statistically different from the rest of the observations in both seasons. Almost all primary caregivers ( $\geq 96 \%$ ) were biological mothers.

PHS mothers/caregivers were slightly older (26.6 ( $\mathrm{SD} 4.4) v .26 \cdot 0$ (SD 5.7) years) compared with the HS sample, while there were more male children ( $57 \% v$. 48\%) in the PHS sample. Infants from the PHS were on average older (9.7 (SD 1.6) v. 8.6 (SD 1.8) months), had a lower mean LAZ and reported more diarrhoeal episodes compared with the HS sample. The majority of the mothers/caregivers in both seasons never attended formal education (Table 1). Continued breast-feeding was reported in all infants included in the present analysis, with no difference between seasons. However, most of them were started with additional foods or drinks earlier than the recommended time ( 6 months of age). The median duration of exclusive breastfeeding was 4.0 (interquartile range 3.0-4.0) months and $4 \cdot 0$ (interquartile range 3.0-6.0) months in HS and PHS, respectively. Of the infants, $88 \%$ and $67 \%(P<0.05)$ were introduced to complementary foods before 6 months during HS and PHS, respectively.

The mean DDS was $2 \cdot 1$ (SD 0.94) and $2 \cdot 3$ (SD 1.1) in HS and PHS respectively. Only $8 \%$ and $13 \%$ of the infants were taking four or more food groups; while $69 \%$ and $63 \%$ of infants were taking two or fewer food groups in the previous day of the interview in HS and PHS, respectively. There was no difference in the recorded DDS between both seasons $(P=0 \cdot 09)$. The mean MMDA was 0.59 (SD 0.15 ) and 0.61 (SD 0.13 ) during HS and PHS, respectively. The relatively low mean MMDA in both seasons is indicative of low micronutrient nutrient density of the complementary foods given to infants. The overall MMDA was significantly lower during the HS $(P=0 \cdot 02)$. However, after adjusting for infant age this difference was not significant (Table 1). 
Table 1 Characteristics of the study population according to season; breast-fed infants aged 6-12 months from the catchment of the Gilgel Gibe Field Research Centre of Jimma University, south-west Ethiopia, October-December 2009 (harvest season; HS) and June-August 2010 (pre-harvest season; PHS)

\begin{tabular}{|c|c|c|c|c|c|}
\hline \multirow[b]{2}{*}{ Variable } & \multicolumn{2}{|l|}{ HS } & \multicolumn{2}{|c|}{ PHS } & \multirow[b]{2}{*}{$P$ value } \\
\hline & $n$, Mean or Median & $\%$, sD or IQR & $n$, Mean or Median & $\%$, SD or IQR & \\
\hline \multicolumn{6}{|l|}{ Sex of the child, $n$ and $\%$} \\
\hline Female & 154 & $52 \cdot 0$ & 125 & 43.0 & 0.03 \\
\hline \multicolumn{6}{|l|}{ Age of the child, $n$ and $\%$} \\
\hline $6-8$ months & 152 & 51.4 & 71 & $24 \cdot 4$ & \multirow[t]{2}{*}{$<0.001$} \\
\hline 9-12 months & 144 & 48.6 & 220 & $75 \cdot 6$ & \\
\hline \multicolumn{6}{|l|}{ Age of the mother, $n$ and $\%$} \\
\hline$<20$ years & 60 & $20 \cdot 6$ & 32 & $11 \cdot 0$ & \multirow[t]{3}{*}{0.004} \\
\hline $20-34$ years & 202 & 69.4 & 233 & $80 \cdot 1$ & \\
\hline$\geq 35$ years & 29 & $10 \cdot 0$ & 26 & 8.9 & \\
\hline \multicolumn{6}{|l|}{ Socio-economic index, $n$ and $\%$} \\
\hline Low & 79 & $27 \cdot 3$ & 115 & 39.9 & \multirow{3}{*}{0.006} \\
\hline Medium & 106 & $36 \cdot 7$ & 89 & $30 \cdot 9$ & \\
\hline High & 104 & $36 \cdot 0$ & 84 & $29 \cdot 2$ & \\
\hline \multicolumn{6}{|l|}{ Under-5 children in the household, $n$ and $\%$} \\
\hline $0-1$ child & 79 & $26 \cdot 7$ & 66 & $22 \cdot 7$ & \multirow{2}{*}{0.26} \\
\hline$\geq 2$ children & 217 & $73 \cdot 3$ & 225 & $77 \cdot 3$ & \\
\hline \multicolumn{6}{|l|}{ Cought, $n$ and $\%$} \\
\hline Yes & 44 & 14.9 & 57 & $19 \cdot 6$ & 0.13 \\
\hline \multicolumn{6}{|l|}{ Fevert, $n$ and $\%$} \\
\hline Yes & 57 & $19 \cdot 3$ & 67 & 23.0 & 0.27 \\
\hline \multicolumn{6}{|l|}{ Diarrhoea,$n$ and $\%$} \\
\hline Yes & 49 & $16 \cdot 7$ & 70 & $24 \cdot 1$ & 0.03 \\
\hline \multicolumn{6}{|l|}{ Source of drinking water for household, $n$ and $\%$} \\
\hline Unsafe water source & 252 & $85 \cdot 1$ & 229 & $78 \cdot 7$ & \multirow[t]{2}{*}{0.04} \\
\hline Safe water source & 44 & 14.9 & 62 & 21.3 & \\
\hline \multicolumn{6}{|l|}{ Human waste disposal by the household, $n$ and $\%$} \\
\hline Improper disposal & 117 & 39.7 & 97 & $33 \cdot 3$ & \multirow[t]{2}{*}{0.11} \\
\hline Proper disposal & 178 & $60 \cdot 3$ & 194 & $66 \cdot 7$ & \\
\hline \multicolumn{6}{|l|}{ Maternal schooling, $n$ and $\%$} \\
\hline Not attended & 243 & $82 \cdot 1$ & 246 & 84.5 & \multirow{2}{*}{0.43} \\
\hline Attended formal school & 53 & $17 \cdot 9$ & 45 & $15 \cdot 5$ & \\
\hline LAZ, mean and SD & -0.77 & 1.4 & -1.00 & 1.3 & 0.02 \\
\hline Stunting, $n$ and $\%$ & & & & & \\
\hline $\mathrm{LAZ}<-2$ & 55 & $18 \cdot 6$ & 61 & $21 \cdot 1$ & 0.44 \\
\hline$\overline{L A Z}<-3$ & 18 & $6 \cdot 1$ & 16 & 5.5 & 0.78 \\
\hline WLZ, mean and SD & -0.63 & 1.3 & -0.75 & 1.3 & 0.28 \\
\hline Wasting, $n$ and $\%$ & & & & & \\
\hline$W L Z<-2$ & 35 & $11 \cdot 8$ & 45 & $15 \cdot 5$ & 0.19 \\
\hline WLZ $<-3$ & 12 & $4 \cdot 1$ & 12 & $4 \cdot 1$ & 0.96 \\
\hline WAZ, mean and SD & -0.96 & 1.2 & $-1 \cdot 10$ & 1.4 & 0.08 \\
\hline Underweight, $n$ and $\%$ & & & & & \\
\hline WAZ $<-2$ & 52 & $17 \cdot 6$ & 75 & $25 \cdot 8$ & \\
\hline WAZ $<-3$ & 18 & $6 \cdot 1$ & 20 & 6.9 & \\
\hline Duration of EBF (months), median and IQR $\ddagger$ & $4 \cdot 0$ & $3-4$ & 4.0 & $3-6$ & $<0.001$ \\
\hline Meal frequency, median and IQR $\ddagger$,§ & $2 \cdot 0$ & $0-3$ & $2 \cdot 0$ & $1-3$ & 0.43 \\
\hline DDS, mean and SD & $2 \cdot 1$ & 0.94 & $2 \cdot 3$ & $1 \cdot 1$ & 0.09 \\
\hline MMDA, mean and SD & 0.59 & 0.15 & 0.61 & 0.13 & 0.02 \\
\hline
\end{tabular}

IQR, interquartile range; LAZ, length-for-age Z-score; WLZ, weight-for-length Z-score; WAZ, weight-for-age Z-score; EBF, exclusive breast-feeding; DDS, dietary diversity score; MMDA, mean micronutrient density adequacy.

†Diarrhoea, cough, fever in the previous 2 weeks before the surveys.

$\ddagger$ Two-sample Wilcoxon rank-sum (Mann-Whitney) test was used to calculate the $P$ value.

$\S$ Frequency of consumption of solid/semi-solid or soft food.

We found important differences in energy and micronutrient intakes between seasons. After adjusting for some sample characteristics which were statistically different between the two seasons, energy, protein, riboflavin, vitamin $\mathrm{C}$ and absorbed $\mathrm{Ca}$ intakes were larger during the PHS than HS (Table 2). In contrast, we found that thiamin intake was lower during the PHS compared with HS. The median intakes of vitamin $\mathrm{A}$, Fe and $\mathrm{Zn}$ were lower than what are recommended from complementary foods, but the energy and protein contributions from complementary foods were higher than the desired values (see online supplementary material, Supplemental Table 1).

Consumption of different food groups varied with DDS. Staples like cereals, tubers and roots were consumed most frequently in both seasons without a lot of discriminatory value between children. Beyond this food group, the DDS increased primarily through the consumption of legumes and dairy (Table 3 ). The majority of the infants consumed 
Table 2 Energy and nutrient intakes of the study population according to season; breast-fed infants aged 6-12 months from the catchment of the Gilgel Gibe Field Research Centre of Jimma University, south-west Ethiopia, October-December 2009 (harvest season; HS) and June-August 2010 (pre-harvest season; PHS)

\begin{tabular}{|c|c|c|c|c|c|c|c|}
\hline \multirow{2}{*}{$\begin{array}{l}\text { Nutrient intake from } \\
\text { complementary food/d }\end{array}$} & \multicolumn{2}{|c|}{ HS } & \multicolumn{2}{|c|}{ PHS } & \multirow[b]{2}{*}{ Mean difference } & \multirow[b]{2}{*}{$95 \% \mathrm{Cl}$} & \multirow[b]{2}{*}{$P$ value } \\
\hline & Median & IQR & Median & IQR & & & \\
\hline Energy (kJ) & 975 & $665-1276$ & 1172 & 824-1452 & 159 & 84,234 & $<0.001$ \\
\hline Energy (kcal) & 233 & 159-305 & 280 & 197-347 & 38 & 20,56 & $<0.001$ \\
\hline Protein $(\mathrm{g})$ & 6.7 & $4 \cdot 5-9 \cdot 2$ & 8.0 & $5 \cdot 1-10 \cdot 6$ & 1.06 & $0.43,1.7$ & 0.001 \\
\hline Vitamin A (RE) & $9 \cdot 0$ & $1 \cdot 2-18 \cdot 0$ & 1.9 & $0.6-11.2$ & $-0 \cdot 14$ & $-3 \cdot 9,3 \cdot 6$ & 0.94 \\
\hline Thiamin (mg) & 0.16 & $0.10-0.22$ & 0.13 & $0.08-0.18$ & -0.03 & $-0.04,-0.02$ & $<0.001$ \\
\hline Riboflavin (mg) & 0.21 & $0.11-0.34$ & 0.29 & $0.13-0.46$ & 0.08 & $0.05,0.11$ & $<0.001$ \\
\hline Vitamin C (mg) & 1.5 & $0.52-3 \cdot 8$ & $4 \cdot 1$ & $2 \cdot 1-7 \cdot 7$ & $2 \cdot 2$ & $0.71,3.70$ & 0.004 \\
\hline Niacin $(\mathrm{mg})$ & 0.67 & $0.35-1.01$ & 0.70 & $0.45-1.2$ & 0.07 & $0.03,0.18$ & 0.17 \\
\hline Absorbed Ca (mg) & 28 & $15-45$ & 34 & $13-58$ & $8 \cdot 0$ & $4 \cdot 0,12 \cdot 0$ & $<0.001$ \\
\hline Absorbed Fe (mg) & 0.69 & $0.24-1.44$ & 1.01 & $0.32-1.65$ & 0.13 & $-0.03,0.29$ & 0.05 \\
\hline Absorbed Zn (mg) & 0.16 & $0.11-0.21$ & 0.17 & $0.11-0.23$ & 0.02 & $0.0003,0.03$ & 0.10 \\
\hline
\end{tabular}

$\mathrm{IQR}$, interquartile range; $\mathrm{RE}$, retinol equivalents.

†Differences in means and $P$ values are obtained from multiple linear regression models adjusting for child age, maternal age and child sex.

Table 3 Distribution of food groups consumed according to dietary diversity score (DDS) and stratified by season; breast-fed infants aged 6-12 months from the catchment of the Gilgel Gibe Field Research Centre of Jimma University, south-west Ethiopia, October-December 2009 (harvest season; HS) and June-August 2010 (pre-harvest season; PHS)

\begin{tabular}{|c|c|c|c|c|c|c|c|c|c|c|c|c|c|c|}
\hline \multirow[b]{2}{*}{ DDS } & \multicolumn{2}{|c|}{$\begin{array}{l}\text { Cereals, tubers } \\
\text { and roots }\end{array}$} & \multicolumn{2}{|c|}{$\begin{array}{l}\text { Legumes } \\
\text { and nuts }\end{array}$} & \multicolumn{2}{|c|}{$\begin{array}{l}\text { Vitamin A-rich fruits } \\
\text { and vegetables }\end{array}$} & \multicolumn{2}{|c|}{$\begin{array}{c}\text { Other fruits } \\
\text { and vegetables }\end{array}$} & \multicolumn{2}{|c|}{ Flesh foods } & \multicolumn{2}{|c|}{ Eggs } & \multicolumn{2}{|c|}{ Dairy } \\
\hline & $n \dagger$ & $\% \ddagger$ & $n$ & $\%$ & $n$ & $\%$ & $n$ & $\%$ & $n$ & $\%$ & $n$ & $\%$ & $n$ & $\%$ \\
\hline \multicolumn{15}{|c|}{ HS (n 296) } \\
\hline 1 & 57 & 74 & 1 & 1 & 0 & 0 & 0 & 0 & 0 & 0 & 1 & 1 & 18 & 23 \\
\hline 2 & 121 & 98 & 27 & 22 & 8 & 7 & 6 & 5 & 1 & 1 & 3 & 2 & 80 & 65 \\
\hline 3 & 67 & 99 & 46 & 68 & 9 & 13 & 18 & 27 & 4 & 6 & 7 & 10 & 53 & 78 \\
\hline 4 & 19 & 100 & 13 & 68 & 9 & 47 & 15 & 79 & 0 & 0 & 4 & 21 & 16 & 84 \\
\hline 5 & 5 & 100 & 5 & 100 & 5 & 100 & 4 & 89 & 1 & 20 & 0 & 0 & 5 & 100 \\
\hline \multicolumn{15}{|c|}{ PHS (n 291) } \\
\hline 1 & 55 & 75 & 1 & 1 & 2 & 3 & 0 & 0 & 0 & 0 & 1 & 1 & 14 & 19 \\
\hline 2 & 104 & 95 & 32 & 29 & $1 \overline{1}$ & 10 & 17 & 16 & 0 & 0 & 4 & 4 & 52 & 47 \\
\hline 3 & 68 & 99 & 46 & 67 & 25 & 36 & 12 & 17 & 1 & 1 & 12 & 16 & 43 & 62 \\
\hline 4 & 29 & 97 & 22 & 73 & 19 & 63 & 18 & 60 & 0 & 0 & 10 & 30 & 18 & 60 \\
\hline 5 & 8 & 100 & 8 & 100 & 6 & 75 & 7 & 88 & 1 & 13 & 3 & 42 & 7 & 88 \\
\hline 6 & 1 & 100 & 1 & 100 & 1 & 100 & 1 & 100 & 0 & 0 & 1 & 100 & 1 & 100 \\
\hline
\end{tabular}

†Total number of infants who consumed each food group.

†Percentage of infants who consumed each food group. Note that the numbers and percentages are not mutually exclusive, as an infant can consume more than one food group at a time.

vitamin A-rich fruits and vegetables, and other fruits and vegetables if their DDS was 3 or higher. Flesh foods including fish were the least consumed by the study children. Further analysis was performed to explain which food groups were responsible for the differences observed in individual nutrient intakes between the two seasons. Dairy was the main source of Ca $(130.6 \mathrm{mg} / \mathrm{d}$ in HS and $167.7 \mathrm{mg} / \mathrm{d}$ in the PHS) in both seasons followed by eggs, other fruits and vegetables, and legumes; while vitamin A-rich fruits and vegetables, and other fruits and vegetables were important contributors of vitamin $C$ intake in both seasons (see online supplementary material, Supplemental Table 2).

In multiple linear regression analysis, we found a significant and positive association between DDS and MMDA irrespective of season after adjusting for important confounders. For an additional increase in DDS by one unit there was an increase in MMDA by $4.5 \%$ and $4.4 \%$ in HS and PHS, respectively (Table 4).

A receiver-operating characteristic curve analysis was performed using the MMDA $<50 \%$ and $\mathrm{MMDA} \geq 75 \%$ cut-offs in both seasons. We found AUC values of 0.64 (95\% CI $0.60,0.67)$ and 0.76 (95\% CI $0.80,0.75)$ for MMDA $<50 \%$ in HS and PHS, respectively. The AUC values for the MMDA $\geq 75 \%$ cut-off were $0.67(95 \% \mathrm{CI}$ $0.53,0.81)$ and 0.58 (95\% CI 0.47, 0.69) in HS and PHS, respectively. All AUC values were significantly higher than a null value of 0.50 for MMDA $<50 \%$ but not for MMDA $\geq 75 \%$ in PHS.

After performing a sensitivity and specificity analysis for the two MMDA cut-offs, we found that a DDS of $\leq 2$ food groups performed best in predicting 'low' MMDA, with 
Table 4 The association between dietary diversity score (DDS) and mean micronutrient density adequacy (MMDA) stratified by seasont; breast-fed infants aged 6-12 months from the catchment of the Gilgel Gibe Field Research Centre of Jimma University, south-west Ethiopia, October-December 2009 (harvest season; HS) and June-August 2010 (pre-harvest season; PHS)

\begin{tabular}{|c|c|c|c|c|c|c|c|c|}
\hline \multirow[b]{2}{*}{ Variable } & \multicolumn{4}{|c|}{ MMDA (HS) } & \multicolumn{4}{|c|}{ MMDA (PHS) } \\
\hline & Crude $\beta$ & $95 \% \mathrm{Cl}$ & Adjusted $\beta$ & $95 \% \mathrm{Cl}$ & Crude $\beta$ & $95 \% \mathrm{Cl}$ & Adjusted $\beta$ & $95 \% \mathrm{Cl}$ \\
\hline $\begin{array}{l}\text { DDS } \\
\text { Age of the child }\end{array}$ & 0.047 & $0.030,0.060^{\star \star \star}$ & 0.045 & $0.028,0.062^{\star \star \star}$ & 0.043 & $0.029,0.057^{\text {***}}$ & 0.044 & $0.031,0.058^{\star * *}$ \\
\hline $\begin{array}{l}6-8 \text { months } \\
9-12 \text { months }\end{array}$ & $\begin{array}{l}\text { Ref. } \\
0.061\end{array}$ & $0.029,0.094^{\star *}$ & $\begin{array}{l}\text { Ref. } \\
0.050\end{array}$ & $0.018,0.082^{\star *}$ & $\begin{array}{l}\text { Ref. } \\
0.021\end{array}$ & $0.010,0.030^{* *}$ & $\begin{array}{c}\text { Ref } \\
0.081\end{array}$ & $0.047,0.110^{\star \star \star}$ \\
\hline $\begin{array}{l}\text { Age of the mother } \\
<20 \text { years } \\
20-34 \text { years } \\
\geq 35 \text { years }\end{array}$ & $\begin{array}{l}\text { Ref. } \\
0.067\end{array}$ & $0.001,0.063^{\star}$ & $\begin{array}{c}\text { Ref. } \\
0.061 \\
0.080\end{array}$ & $\begin{array}{l}0.016,0.100^{\star *} \\
0.016,0.140^{\star}\end{array}$ & & & & \\
\hline
\end{tabular}

Ref., reference category.

${ }^{\star} P<0.05,{ }^{* \star} P<0.01,{ }^{* \star *} P<0.001$.

†Adjustments were made for socio-economic index, child age, maternal age, maternal schooling, diarrhoea, cough, fever, sex and height-for-age Z-score. Variables for which an association was found for at least one season are tabulated.

$84 \%$ and $92 \%$ sensitivity, $36 \%$ and $43 \%$ specificity, and $47 \%$ and $51 \%$ correct classification in HS and PHS, respectively. The prediction of DDS for 'low' MMDA remained valid when the analysis was disaggregated by age groups in both seasons (Fig. 1). A DDS of $\geq 3$ produced a trade-off between sensitivity and specificity values to predict 'higher' MMDA with relatively low misclassification; but the sensitivity values were rather small (32\% in HS and $24 \%$ in PHS). Age-adjusted receiveroperating characteristic curve analysis was performed to predict 'higher' MMDA, but we could not find an acceptable trade-off between sensitivity and specificity in both seasons as a very small proportion of the infants $(6.4 \%$ in HS and $8.6 \%$ in PHS) achieved MMDA $\geq 75 \%$.

\section{Discussion}

The present study showed that a DDS calculated from seven food groups is able to predict diet quality expressed in terms of micronutrient density adequacy in breast-fed infants, and that seasonality did not alter this relationship, notwithstanding the significant difference in intakes of most the nutrients between seasons.

The regression analysis showed a significant association between DDS and MMDA in both seasons. After adjusting for maternal, socio-economic and child factors, there was no major attenuation of the regression coefficients. A positive association between DDS and dietary quality, albeit expressed by different indicators or scores, among breast-fed and non-breast-fed children was demonstrated previously by other authors with different correlation coefficients $^{(10,12,13,36)}$. However, most such studies were conducted during a specific season, which hampers external validity. Other studies pooled data over different seasons but did not present data on seasonal confounding ${ }^{(10,11,37)}$.

There was a relatively higher mean nutrient intake per food group consumed for most of the nutrients in the PHS compared with HS. However, no difference in DDS and (a)

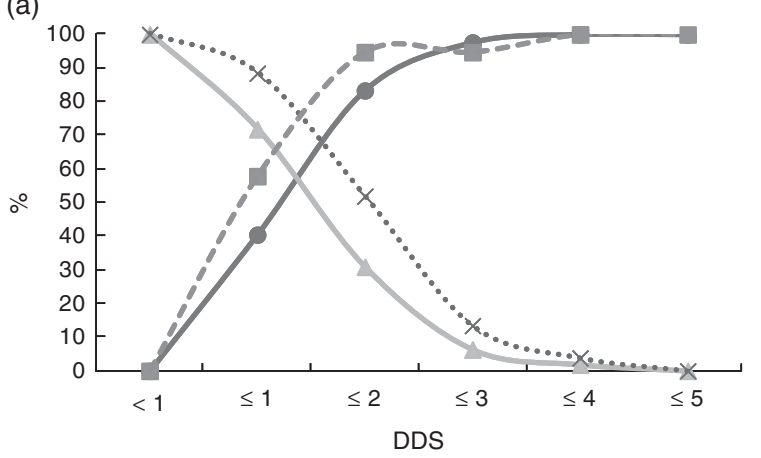

(b)

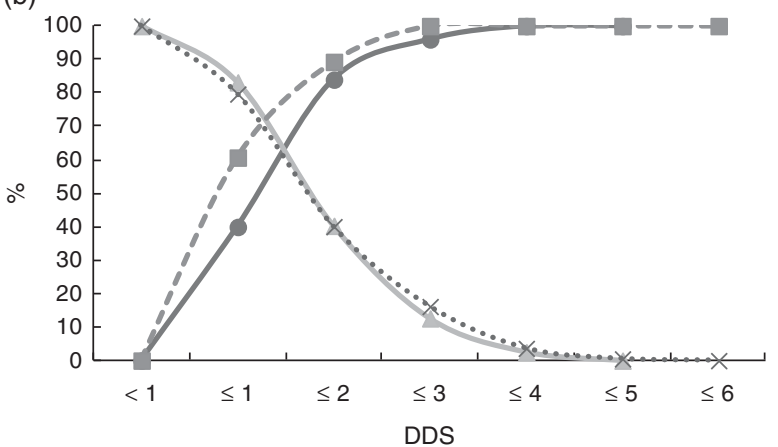

Fig. 1 Sensitivity and specificity of the dietary diversity score (DDS) to predict 'low' nutrient intake, i.e. mean micronutrient density adequacy (MMDA) $<50 \%$, for breast-fed infants aged 6-8 months (a) and 9-12 months (b) from the catchment of the Gilgel Gibe Field Research Centre of Jimma University, southwest Ethiopia, October-December 2009 (harvest season) and June-August 2010 (pre-harvest season). —-, SeHS (sensitivity in the harvest season); —, SpHS (specificity in the harvest season); - -- , SePHS (sensitivity in the preharvest season); $\cdots \times \cdots$, SpPHS (specificity in the pre-harvest season). Sensitivity indicates the percentage of children having 'low' MMDA who are identified as such by DDS; specificity indicates the percentage of children who are above the cut-off for 'low' MMDA and are correctly identified as such by DDS

age-adjusted MMDA was noted between the two seasons. On the other hand, some food groups like flesh foods and dairy were consumed less frequently during the PHS. 
These two observations suggest that the relatively higher overall nutrient intake during the PHS was mainly the consequence of larger average portion sizes and/or a higher intra-day frequency of food group consumption. Cereals, tubers and roots were the most commonly consumed foods in both seasons in the present study. Similar observations were made in other developing countries $^{(10,12)}$. However, there was inconsistency regarding the consumption pattern of other food groups in relation to DDS in the present study, in which dairy and flesh foods were relatively more consumed in the HS.

The mean MMDA for our study sample was suboptimal, indicating inadequate intake of one or more micronutrients. In a similar analysis in the same age group in Madagascar $^{(10)}$, most of the nutrients were taken in amounts less than desired. Another study conducted during the PHS in southern Ethiopia demonstrated that all nutrients measured were significantly lower than the 'estimated need' calculated $^{(5)}$ even if comparable reference values were used to calculate the 'estimated need' adjusted for age and body weight. The dietary reference intake value for Ca used in our study was based on an adequate intake ${ }^{(31)}$ which is lower than the $\mathrm{WHO}^{(28)}$ and $\mathrm{FAO} / \mathrm{WHO} /$ United Nations University ${ }^{(38)}$ reference values used in the study in southern Ethiopia. Furthermore, the significant gap between actual intake and desired/estimated need could be due to a relatively high prevalence of chronic food insecurity in that part of south Ethiopia compared with our study area ${ }^{(39)}$. Overall, the density approach of MMDA allows to adjust for the unknown breast milk intake assuming a balance between energy intake from both complementary foods and breast milk, and assuming average breast milk intake levels as proposed by $\mathrm{WHO}^{(28)}$. Consequently, if actual breast milk intake is less than the proposed average, calculations show a higher mean desired nutrient density and desired intake, which implies lower MMDA and higher deficits between desired and actual intakes of energy and nutrients.

We did not find important differences in MMDA and DDS, between PHS and HS. Conversely, with the exception of vitamin A and thiamin, energy and nutrient intakes were generally higher during the PHS compared with the HS. This finding was rather unexpected as previous studies suggest that the PHS is characterized by a relatively higher level of household food insecurity ${ }^{(40)}$, the latter being expected to be associated with more suboptimal energy and nutrient intakes. However, we found that the number of meals given to the average child was similar during PHS and HS. As we did not collect household food insecurity indicators, it remains unclear if either our study area is not suffering from previously reported fluctuations in food insecurity, or if household food insecurity during the PHS does not trickle down to the child's energy and nutrient intakes.

In the present study, a DDS $\leq 2$ food groups was a better predictor of 'low' micronutrient density adequacy. This finding is in good agreement with a previous analysis from a ten-country study ${ }^{(37)}$ and was subsequently proposed by others $^{(10)}$. Increasing the cut-off of DDS increased sensitivity at the expense of specificity, and higher percentage misclassification. In a country like Ethiopia with high rates of micronutrient malnutrition, the trade-off for higher sensitivity could be more important in order to screen children at risk of micronutrient deficiencies and include them in nutrition intervention programmes, such as targeted supplementation or promotion of appropriate infant and young child feeding. However, with limited preventive nutrition programmes, one should not compromise specificity as more sensitivity implies more false positives. Hence, the trade-off between sensitivity and specificity depends on the desired purpose of the DDS. Based on a series of analyses of data sets from developing countries, WHO developed indicators for assessment of infant and young child feeding practices in which consumption of four or more food groups was considered to be associated with a good-quality diet ${ }^{(17)}$. Nevertheless, the utility of DDS to classify children with 'higher' intake was not ascertained in our analysis. This was mainly due to the observation that only $2 \%$ and none of the infants aged 6-8 months had achieved MMDA $\geq 75 \%$ in HS and PHS, respectively. The overall proportions of study infants who were correctly classified with 'low' or 'higher' intake by DDS were also relatively low compared with previous analyses $^{(10,37)}$ in which larger samples were used to validate DDS with $1 \mathrm{~g}$ and $10 \mathrm{~g}$ minimum limits.

The current study has a number of strengths and limitations to consider. In the evaluation of the performance of DDS as an indicator of child dietary quality expressed in terms of MMDA, we ran regression analyses by taking into account all measured covariates. In contrast to previous studies, our study also used two $24 \mathrm{~h}$ dietary recalls to collect data on quantitative nutrient intake. This offers a better estimation of the usual intake distribution at the population level. We were limited to compile MMDA based on data availability for only eight micronutrients in Ethiopia. However, most of the micronutrients of public health importance were included. We did not estimate individual breast milk intake, but rather we used the age-adjusted mean intake as proposed by the WHO guideline $^{(28)}$. For that reason, we opted to convert the intakes into MDA values that are inversely associated with the energy contribution from breast milk.

\section{Conclusions}

We found a positive association between dietary diversity and micronutrient density adequacy and energy intake from complementary foods and this association remained stable over seasons. This exercise once more corroborates previous findings that low dietary diversity scores indicate a qualitatively poor diet in young children. In areas where there are limited resources, the dietary diversity score can 
give a rough idea on micronutrient intake, irrespective of the agricultural seasons which influence food availability over the year. For more detailed information on prevalence and type of micronutrient deficiency, more rigorous approaches should be used.

\section{Acknowledgements}

Acknowledgements: The authors thank supervisors, data collectors and mothers, and the tonal and local administration. They are also grateful for the contribution of the Gilgel Gibe Field Research Centre of Jimma University for providing background information to conduct the census in the study area. Financial support: The study was financed by VLIR-UOS (http://www.vliruos.be/) through the Institutional University Cooperation Programme of Jimma University (Ethiopia). VLIR-UOS had no role in the design, analysis or writing of this manuscript. Conflict of interest: None. Authorship: M.W., P.K. and K.P.B. designed the study, supervised if the data were collected as per the protocol and contributed to the actual implementation of the study. M.W. acquired the data from the field. L.H. and C.L. supported in the analysis and interpretation of the data. M.W. drafted the manuscript. All authors have read and approved the final manuscript for submission. Ethics of buman subject participation: This study was conducted according to the guidelines laid down in the Declaration of Helsinki and all procedures involving human subjects/patients were approved by the Ethics Review Board of Jimma University, Ethiopia (reference number RPGC/104/2002) and the Ethics Committee of Ghent University Hospital, Belgium (Belgian registration number B67020109188). Informed verbal consent was secured from the mothers/caregivers before conducting the interviews. Verbal consent was witnessed and formally recorded.

\section{Supplementary material}

To view supplementary material for this article, please visit http://dx.doi.org/10.1017/S1368980016000525

\section{References}

1. Central Statistical Agency, Ethiopia \& ORC Macro (2011) Ethiopia Demographic and Health Survey 2011. Addis Ababa and Calverton, MD: CSA and ORC Macro.

2. Black RE, Allen LH, Bhutta ZA et al. (2008) Maternal and child undernutrition: global and regional exposures and health consequences. Lancet 371, 243-260.

3. Rajkumar AS, Gaukler C \& Tilahun J (2012) Combating Malnutrition in Ethiopia: An Evidence-Based Approach for Sustained Results. Africa Human Development Series. Washington, DC: The World Bank.

4. Hotz C \& Brown K (2004) International Zinc Nutrition Consultative Group (IZiNCG) technical document \#1. Assessment of the risk of zinc deficiency in populations and options for its control. Food Nutr Bull 25, 94-203.
5. Gibson RS, Abebe Y, Hambidge KM et al. (2009) Inadequate feeding practices and impaired growth among children from subsistence farming households in Sidama, Southern Ethiopia. Matern Child Nutr 5, 260-275.

6. Abebe Y, Bogale A, Hambidge KM et al. (2007) Phytate, zinc, iron and calcium content of selected raw and prepared foods consumed in rural Sidama, Southern Ethiopia, and implications for bioavailability. J Food Compost Anal 20, 161-168.

7. Gibson RS, Ferguson EL \& Lehrfeld J (1998) Complementary foods for infant feeding in developing countries: their nutrient adequacy and improvement. Eur J Clin Nutr $\mathbf{5 2}$, $764-770$

8. Gibson RS (1990) Principles of Nutritional Assessment. New York: Oxford University Press.

9. Kourlaba G \& Panagiotakos DB (2009) Dietary quality indices and human health: a review. Maturitas 62, 1-8.

10. Moursi M, Arimond M, Dewey K et al. (2008) Dietary diversity is a good predictor of the micronutrient density of the diet of 6- to 23-month-old children in Madagascar. J Nutr 138, 2448-2453.

11. Dewey KG, Cohen RJ, Arimond M et al. (2006) Developing and Validating Simple Indicators of Complementary Food Intake and Nutrient Density for Breastfed Children in Developing Countries. Washington, DC: Food and Nutrition Technical Assistance Project, Academy for Educational Development.

12. Kennedy GL, Pedro MR, Seghieri C et al. (2007) Dietary diversity score is a useful indicator of micronutrient intake in non-breast-feeding Filipino children. J Nutr 137, 472-477.

13. Steyn N, Nel J, Nantel G et al. (2006) Food variety and dietary diversity scores in children: are they good indicators of dietary adequacy? Public Health Nutr 9, 644-650.

14. Moursi M, Martin-Prevel Y, Eymard-Duvernay S et al. (2008) Assessment of child feeding practices using a summary index: stability over time and association with child growth in urban Madagascar. Am J Clin Nutr 87, 1472-1479.

15. Winichagoon P (2008) Limitations and resolutions for dietary assessment of micronutrient intakes. Asia Pac J Clin Nutr 17, 296-298.

16. Central Statistical Agency, Ethiopia \& ORC Macro (2006) Ethiopia Demographic and Health Survey 2005. Addis Ababa and Calverton, MD: CSA and ORC Macro.

17. World Health Organization (2008) Indicators for Assessing Infant and Young Child Feeding Practices. Part I: Definitions. Conclusions of a Consensus Meeting held 6-8 November 2007 in Washington DC, USA. Geneva: WHO.

18. Gibson RS \& Ferguson EL (2008) An Interactive 24-Hour Recall for Assessing the Adequacy of Iron and Zinc Intakes in Developing Countries. Washington, DC: International Life Sciences Institute.

19. Ethiopian Nutrition Institute (Ministry of Health) (1980) Ethiopian Traditional Recipes, 1st ed. Addis Ababa: ENI.

20. Ethiopian Health and Nutrition Research Institute (1998) Food Composition Table for Use in Ethiopia. Part IV. 1995-1997. Addis Ababa: EHNRI/FAO.

21. Ethiopian Health and Nutrition Research Institute (1998) Food Composition Table for Use in Ethiopia. Part III. 1995-1997. Addis Ababa: EHNRI/FAO.

22. Food and Agriculture Organization of the United Nations (1968) Food Composition Table for Use in Africa. Rome: FAO.

23. West CE, Pepping F, Temalilwa CR et al. (1988) The Composition of Foods Commonly Eaten in East Africa. Wageningen: Wageningen Agricultural University.

24. US Department of Agriculture, Agricultural Research Service (2010) USDA National Nutrient Database for Standard Reference, Release 23. Nutrient Data Laboratory Home Page. http://www.ars.usda.gov/ba/bhnrc/ndl (accessed March 2016). 
25. Dewey KG \& Brown KH (2003) Update on technical issues concerning complementary feeding of young children in developing countries and implications for intervention programs. Food Nutr Bull 24, 5-28.

26. Department of Food Safety and Quality, Ghent University (2014) Lucille Version 1. http://www.foodscience.ugent.be/ nutriFOODchem/foodintake (accessed March 2016).

27. World Health Organization (2010) Indicators for Assessing Infant and Young Child Feeding Practices: Part II. Measurement. Geneva: WHO.

28. World Health Organization (1998) Complementary Feeding of Young Children in Developing Countries: A Review of Current Scientific Knowledge. WHO/NUT/98.1. Geneva: WHO.

29. Food and Agriculture Organization of the United Nations/ World Health Organization (2004) Vitamin and Mineral Requirements in Human Nutrition, 2nd ed. Rome and Geneva: FAO and WHO.

30. World Health Organization (1996) Trace Elements in Human Nutrition and Health. Geneva: WHO.

31. Institute of Medicine (1997) Dietary Reference Intakes for Calcium, Phosphorus, Magnesium, Vitamin D, and Fluoride. Washington, DC: National Academy Press.

32. Domellöf M, Lönnerdal B, Abrams SA et al. (2002) Iron absorption in breast-fed infants: effects of age, iron status, iron supplements, and complementary foods. Am J Clin Nutr 76, 198-204.

33. Institute of Medicine (2001) Dietary Reference Intakes for Vitamin A, Vitamin K, Arsenic, Boron, Chromium, Copper, Iodine, Iron, Manganese, Molybdenum, Nickel, Silicon, Vanadium, and Zinc. Washington, DC: National Academy Press.
34. World Health Organization (2010) WHO Anthro for Personal Computers, Version 3.2.2, 2011: Software and Macros for Assessing Growth and Development of the World's Children. Geneva: WHO; available at http://www. who.int/childgrowth/software/en/

35. Vyas S \& Kumaranayake L (2006) Constructing socioeconomic status indices: how to use principal components analysis. Health Policy Plan 21, 459-468.

36. Hatloy A, Torheim L \& Oshaug A (2002) Food variety a good indicator of nutritional adequacy of the diet? A case study from an Urban Area in Mali, West Africa. Eur J Clin Nutr 52, 891-898.

37. Working Group on Infant and Young Child Feeding Indicators (2006) Developing and Validating Simple Indicators of Dietary Quality and Energy Intake of Infants and Young Children in Developing Countries: Summary of Findings from Analysis of 10 Data Sets. Washington, DC: Food and Nutrition Technical Assistance Project, Academy for Educational Development.

38. Food and Agriculture Organization of the United Nations/ World Health Organization/United Nations University (2004) Human Energy Requirements, FAO Food and Nutrition Technical Report Series no. 1. Rome: UNU/WHO/ FAO.

39. Regassa N \& Stoecker BJ (2012) Household food insecurity and hunger among households in Sidama district, southern Ethiopia. Public Health Nutr 15, 1276-1283.

40. Hirvonen K, Taffesse AS \& Worku Hassen I (2015) Seasonality and household diets in Ethiopia. Public Health Nutr (Epublication ahead of print version). 